\title{
Factors Related to Return to Work in Women After Breast Cancer in Iran
}

\author{
Fatemeh Azarkish, ${ }^{1}$ Khadijeh Mirzaii Najmabadi, ${ }^{2,}{ }^{*}$ Robab Latifnejad Roudsari, ${ }^{2}$ and Fate- \\ meh Homaei Shandiz ${ }^{3}$ \\ 1 Iranshahr University of Medical Sciences, Iranshahr, IR Iran \\ ${ }^{2}$ Department of Midwifery, School of Nursing and Midwifery, Mashhad University of Medical Sciences (MUMS), Mashhad, IR Iran \\ ${ }^{3}$ Cancer Research Center, Faculty of Medicine, Mashhad University of Medical Sciences (MUMS), Mashhad, IR Iran \\ *Corresponding Author: Khadijeh Mirzaii Najmabadi, Department of Midwifery, School of Nursing and Midwifery, Mashhad University of Medical Sciences (MUMS), Mashhad, IR Iran. \\ Tel:+98-5118546025, Fax:+98-5118597313, E-mail: MirzaiiKH@mums.ac.ir
}

Received: May 11, 2014; Revised: June 18, 2014; Accepted: July 3, 2014

\begin{abstract}
Background: Most women are diagnosed with breast cancer (BC) when they are still at the appropriate age for employment. The increasing survival rates of patients with BC call for more attention to their ability to return to work.

Objectives: The aim of this study was to identify factors related to the return to work in Iranian women underwent $\mathrm{BC}$ treatment.

Patients and Methods: A total of 175 women with BC, who met the inclusion criteria, were enrolled in this cross-sectional study. The subjects were recruited from four hospitals affiliated to Mashhad university of medical sciences. These hospitals are oncology referral centers in eastern Iran. All records of employed women with BC were studied in four hospitals of Mashhad city, Iran, during 2000 2010. The researchers designed a questionnaire, which consisted of questions regarding social/demographic, health/disease, and work characteristics. The questionnaires were completed through interviews. Data were analyzed using SPSS software, version 11.5.

Results: The mean age of the patients at the time of interview was $44.3 \pm 6.72$ years. Mean age of "Return-to-work" group was 42.71 and "No return-to-work" group was 51.06. Most women (80\%) were married. At the time of the interview, $80 \%$ had returned to work after a BC diagnosis. Older patients $(\mathrm{OR}=0.796 ; 95 \% \mathrm{CI}, 0.625-0.907, \mathrm{P}=0.002)$, and those with a great deal of work experience $(\mathrm{OR}=0.861 ; 95 \% \mathrm{CI}$, $0.752-0.986, \mathrm{P}=0.030)$ were less likely to return to work. Also, women who had no pain or surgery scar $(\mathrm{OR}=23.03 ; 95 \% \mathrm{CI}, 4.53-117.02, \mathrm{P}<$ $0.001)$ as well as those who had no lymphedema after the $\mathrm{BC}$ treatment were more likely to return to work $(\mathrm{OR}=22.373 ; 95 \% \mathrm{CI}, 4.04-23.892$, $\mathrm{P}<0.001$.

Conclusions: The results of this study show the factors related to the return-to-work after BC treatment in working women in Mashhad city, Iran. These predictors should be taken into account in order to improve the patient's life quality.
\end{abstract}

Keywords: Return to Work; Breast Cancer; Women; Iran

\section{Background}

Most women are diagnosed with breast cancer (BC) when they are still at an employable age, and a good prognosis assures them of a long life expectancy after recovery from the disease (1). In the past few decades, the survival rate steadily has increased for most cancer patients (2).

Modern medicine facilitates not only an early diagnosis of cancer but also treatments that have fewer detrimental impacts on patients' daily lives and functions (3). At the same time, research has more clearly identified longterm medical and behavioral effects of cancer (4).

Cancer survivors view working as a vital part of their lives. In fact, it helps them normalize their lives and cope with the illness (5). While working, survivors regain a sense of control over their lives. Thus, working is believed to act as a coping mechanism for survivors in managing psychosocial tensions and economical aspects of the disease $(4,6)$.

The increasing survival rates in patients with $\mathrm{BC}$ have created a need for more research and advocacy into their ability to return to work after cancer (7). Evidence shows that most employed BC survivors are able to return to work $(3,8,9)$. However, survivors face difficulties at work due to physical or cognitive limitations (10). Return-towork (RTW) can be considered a type of social recovery that enhances the patient's life quality (11).

Personal and medical factors greatly affect the return to work (12). Some research has claimed that there is no association between RTW in cancer survivors and their socio-demographic characteristics, such as age, gender, education, income and marital status (9).

Thus, a negative association exists between RTW and certain types of work, particularly manual work (7). In contrast, social support and an encouraging working environment facilitate the RTW process (13). Discretion during working hours and the amount of work were also positively related to RTW in cancer survivors (11).

Breast cancer and its attendant therapies may cause physical and mental issues that impede going back to work (14). Surgery and radiotherapy of regional nodes

Copyright (C) 2015, Iranian Red Crescent Medical Journal. This is an open-access article distributed under the terms of the Creative Commons Attribution-NonCommercial 4.0 International License (http://creativecommons.org/licenses/by-nc/4.0/) which permits copy and redistribute the material just in noncommercial usages, provided the original work is properly cited. 
may cause secondary effects, such as enema and other arm-related problems. Further, chemotherapy may cause fatigue and cognitive dysfunction (15). These secondary effects may influence working ability, even after the treatments are complete (5). In one study, women diagnosed with early-stage BC were absent from work for about 11.4 months, on average, due to the disease (9). It was confirmed that the treatment, especially chemotherapy, strongly contributed to absence (14).

In 2006, the population of Iran was 70,495,789, including 34,629,420 female citizens (16). According to Iranian Cancer Society statistics, 3,645 new cases of invasive BC were diagnosed from 1998 to 2002 (17). In Iran, BC affects women at least one decade earlier than their counterparts in developed countries (18). In Tehran, in 1998, the breast cancer-induced mortality rate was 5.8 per 100,000 women. A total of 7,762 women died of BC in over 18 provinces of Iran in 2001 (19).

Regardless of all adverse consequences of chemotherapy, today, many patients aim to lead a fruitful life (20). The increasing survival rates of patients with $\mathrm{BC}$ call for more attention to their ability to return to work (9). A better understanding of the RTW process and its predictors for women with BC can enable caregivers to improve patients' working life quality after recovery (12). Most studies on BC have used a quantitative approach $(6,21)$. However, in Iran, no quantitative or qualitative study has been carried out on RTW factors that influence women who have been diagnosed with BC at an employable age $(18,22,23)$.

\section{Objectives}

The aim of this study was to identify factors related to the RTW after BC treatment in women in Mashhad City, Iran.

\section{Patients and Methods}

This cross-sectional study was conducted on 175 working women with BC in four hospitals of Imam Reza, Ghaem, Omid, Mehr and Imam Reza Charity Center affiliated to Mashhad University of Medical Sciences, Mashhad, Iran, the referral centers of oncology in eastern regions of Iran, to determine factors related to RTW in working women with BC during 2000 - 2010. Razavi Khorasan Province is in north-eastern of Iran, and has a population of $\sim 5.9$ million (Statistical Center of Iran). The hospitals included in this study are cancer treatment centers in Khorasan Razavi province, which serve as referral sites for cancer patients in northeast of Iran. All BC records of employed women were studied at four hospitals in Mashhad city, Iran, between 2000 and 2010. Women were included in the study if they met the following inclusion criteria: i) They were Iranian nationals; ii) They could speak and complete the interview; iii) They were within the age range of 20 - 60 years; and iv) They were employed for at least six months before the diagnosis of BC. Patients were excluded if (a) they were housewives, (b) they did not have governmental jobs or (c) they retired after their diagnosis (Figure 1, flow diagram of the study). This study was approved by the ethics committee of Mashhad University of Medical Sciences (registration code: 910215). Written consents were obtained from many of the subjects, and in case the participants were not present at the hospital, verbal consents were obtained.

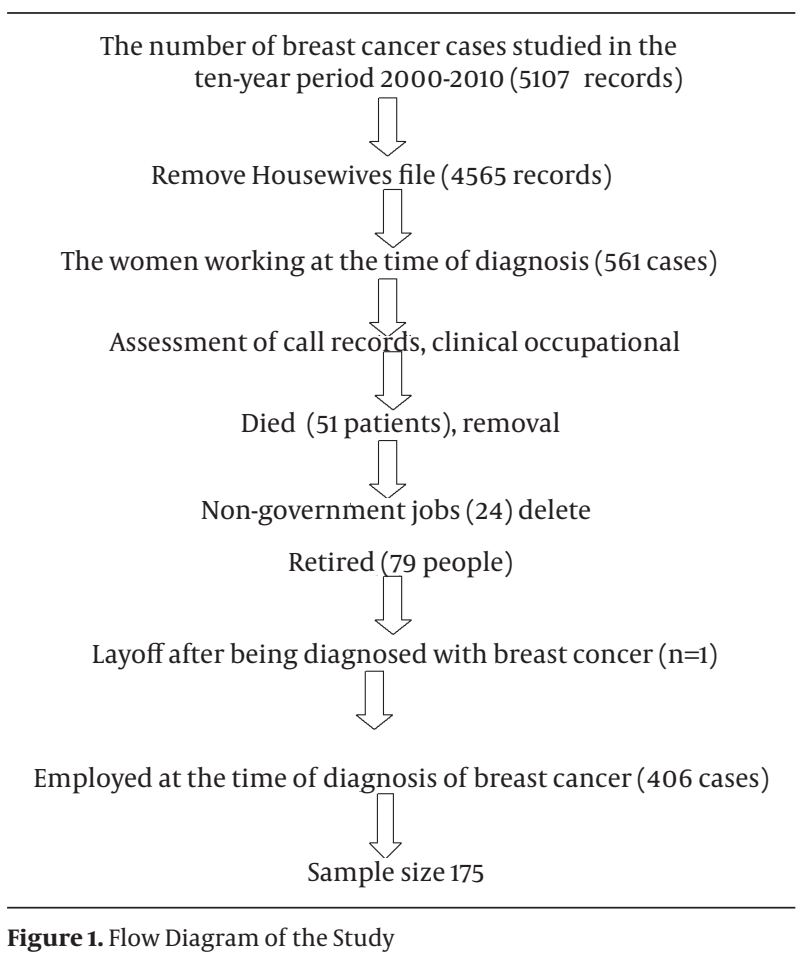

Figure 1. Flow Diagram of the Study

In this study, conducted during 2000 - 2010, study population consisted of all women with BC. The subjects were selected based on the inclusion and exclusion criteria. By using a sample size formula, the size of each group was estimated to be 34 subjects. In the "no return-to-work" group, sampling was continued until reaching the desired sample size, and a total of 175 subjects were enrolled.

$$
n=\frac{\left(z_{1-\frac{\alpha}{2}}+z_{1-\beta}\right)^{2} \times\left[p_{1}\left(1-p_{1}\right)+p_{2}\left(1-p_{2}\right)\right]}{\left(p_{1}-p_{2}\right)^{2}}
$$

$05 / 0=\alpha, 96 / 1 \mathrm{Z1}-\alpha / 2=1 / 96,2 / 0=\beta, 86 / 0 \mathrm{Z1}-\beta=0 / 86, \mathrm{p} 1$ $=34 \%, \mathrm{p} 2=66 \%$.

The researcher-made questionnaire consisted of sociodemographic characteristics, health/disease status, and work conditions. In order to design the questionnaire, 10 faculty members and 10 patients were consulted.

To assess validity of the questionnaire in this study, we used qualitative content analysis. Questionnaires were sent to ten specialists in the field of the study and the material was revised and improved according to the feedbacks received. In order to ensure the collection of data from medical records, a peer researcher extracted the data and reported the consistency of the data (all data 
were collected by one researcher).

The questionnaire included demographic characteristics, health/disease status, and work conditions (e.g., age, marital status, education level, pain and edema in hands after surgery, occupational status, work experience, and RTW). Demographic and work-related data were collected via interviews, and disease-related data were extracted from medical records at the hospitals. In order to gain reliability of questionnaire in this study, test-retest method with 10 day interval was used in which 10 women were asked to complete the questionnaire. The correlation coefficient was calculated to be $85 \%$. The reliability of questions, extracted from medical records, was also examined by test-retest, based on the evaluators' interpretations. The correlation coefficient was calculated to be $89 \%$. The main finding of this study was RTW one year after BC treatment. Return-to-work was defined according to patients' positive response to a question concerned with their occupational status. The statistical analyses were made using the SPSS software, version 11.5. Basic descriptive statistics including mean, standard deviation (SD), and frequencies were measured. Statistical tests such as the independent t-test and chi-square test were used. Regression logistic analysis was used to determine factors (socio-demographic, disease and work variables) related to the RTW after treatment of $\mathrm{BC}$ in working women in Iran.

\section{Results}

Table 1 lists the characteristics of the participants. The mean age of sampling at the time of interview was $44.3 \pm 6.72$ years, but the mean age of the RTW group was 42.71 years and "no return to work" group was 51.06 years. More than $74 \%$ of the participants had a college degree. Job experiences in return to work and "no return to work" groups were 17.47 and 25.23 years, respectively. Only a small proportion of women (10 women, $<10 \%$ ) did not respond to the questionnaire. Data related to all patients were available, except for the missing cases.

Table 1. Characteristics of Employed Women Breast Cancer Survivors

\begin{tabular}{|c|c|c|c|}
\hline Variable & "Return-to- work" group & "No return-to- work" group & P Value \\
\hline Age, $y^{a}$ & $42.71 \pm 6.07$ & $51.06 \pm 4.7$ & $<0.001$ \\
\hline Education & & & $<0.001$ \\
\hline No college degree & $26(18.6)$ & $18(51.4)$ & \\
\hline College degree & $114(81.4)$ & $17(48.6)$ & \\
\hline Experience, $\mathrm{y}^{\mathrm{a}}$ & $17.47 \pm 7.02$ & $25.23 \pm 5.75$ & $<0.001$ \\
\hline Marital status & & & 0.201 \\
\hline Married & $121(86.4)$ & $33(94.3)$ & \\
\hline Single & $19(13.6)$ & $2(5.7)$ & \\
\hline $\begin{array}{l}\text { Physical health before the } \\
\text { diagnosis of breast cancer }\end{array}$ & & & 0.406 \\
\hline Average/poor/very bad & $4(2.9)$ & $2(5.7)$ & \\
\hline Excellent/very good & $136(97.1)$ & $33(94.3)$ & \\
\hline Mastectomy & & & 0.618 \\
\hline Yes & $98(70)$ & $26(74.3)$ & \\
\hline No & $42(30)$ & $9(25.7)$ & \\
\hline Support of husband & & & 0.292 \\
\hline Yes & $108(77.1)$ & $24(68.6)$ & \\
\hline No & $32(22.9)$ & $11(31.4)$ & \\
\hline Support of Colleagues & & & 0.820 \\
\hline Yes & $73(52.1)$ & $19(54.3)$ & \\
\hline No & $67(47.9)$ & $16(45.7)$ & \\
\hline Support of boss/manager & & & 0.104 \\
\hline Yes & $120(85.7)$ & $26(74.3)$ & \\
\hline No & $20(14.3)$ & $9(25.7)$ & \\
\hline Sick leave & & & 0.530 \\
\hline Yes & $125(89.3)$ & $33(94.3)$ & \\
\hline No & $15(10.7)$ & $2(5.7)$ & \\
\hline Pain in scar surgery & & & $<0.001$ \\
\hline Yes & $15(10.7)$ & $24(68.6)$ & \\
\hline No & $125(89.3)$ & $11(31.4)$ & \\
\hline Lymphedema & & & $<0.001$ \\
\hline Yes & $23(16.4)$ & $22(62.9)$ & \\
\hline No & $117(83.6)$ & $13(37.1)$ & \\
\hline
\end{tabular}


Job experiences in the RTW and "no return to work" groups were 17.47 and 25.23 years, respectively. Most women were married (80\%), and more than $94 \%$ reported very well to excellent health before their BC diagnoses. More than $70 \%$ of the patients had undergone a mastectomy. Most women reported receiving support from their husbands, colleagues and managers/bosses after their diagnoses. Less than $10 \%$ had refrained from using sick leave after learning of their BC. The difference in pain during scar surgery, lymphedema and heavy lifting was statistically significant between the two groups $(P<0.001)$. Most of the women were teachers. The mean duration of sick leave was $104.35 \pm 99.23$ days. At the time of the interview, $80 \%$ had returned to work after their treatments. Among the women who had returned to work, over $80 \%$ had resumed their previous job, but $9.2 \%$ had changed job responsibilities, 7.1\% had decreased their working hours and 3.7\% had increased their hours and responsibility. Moreover, $92 \%$ of the women who had returned to work reported experiencing fatigue. Older patients $(\mathrm{OR}=$ 0.796; 95\% CI, 0.625 - 0.907, P = 0.002), and high-work experience $(\mathrm{OR}=0.861 ; 95 \% \mathrm{CI}, 0.752-0.986, \mathrm{P}=0.030)$ were less likely to return to work. Women who had supportive managers or bosses were more likely to return to $(\mathrm{OR}=$ 22.47; 95\% CI, 2.470 - 74.55, P < 0.001). Finally, women who had experienced no pain during scar surgery $(\mathrm{OR}=23.03$; $95 \% \mathrm{CI}, 4.53$ to $117.02, \mathrm{P}<0.001)$ or lymphedema after treatment of $\mathrm{BC}(\mathrm{OR}=22.373 ; 95 \% \mathrm{CI}, 4.04$ to $23.892, \mathrm{P}<0.001)$ were more likely to return to work (Table 2).

Table 2. Logistic Regression Analysis of Return to Work (RTW) After Treatment of Breast Cancer in Working Women Survivors ${ }^{\text {a }}$

\begin{tabular}{lccc}
\hline Variable & OR & $\mathbf{9 5 \%} \mathbf{C l}$ & PValue \\
\hline Age, $y$ & -0.263 & $0.625-0.907$ & 0.002 \\
Experience, $\mathbf{y}$ & -0.150 & $0.752-0.986$ & 0.030 \\
No pain in scar surgery & 3.137 & $4.53-117.02$ & $<0.001$ \\
\hline No lymphedema & 3.118 & $4.04-23.892$ & $<0.001$ \\
\hline Manager/boss support & 3.313 & $2.470-74.55$ & $<0.001$ \\
\hline
\end{tabular}

a Abbreviations: OR, Odds Ratio; CI, Confidence interval.

\section{Discussion}

This study analyzed predictors of RTW in employed Iranian women after a BC treatment. During a period of ten years (2000 - 2010), 80\% of employed women from the study sample returned to work after having BC. Our descriptive results are comparable to those of most studies, particularly to Roelen's, in which $88 \%$ of the respondents returned to work, indicating that a number of women choose to work following their BC diagnoses $(1,3,8,24)$. Other studies reported a rate of work resumption between $64 \%$ and $88 \%(6,14,21,25)$. In 2006 , Bouknight and colleagues reported an $82 \%$ RTW rate for women with BC at 12 months postdiagnosis and $83 \%$ at 18 months. Maun- sell and colleagues reported a rate of $79 \%$ at three years after BC diagnosis; Satariano and colleagues reported 72\% at three months after BC diagnosis, and Johnsson confirmed that $84 \%$ RTW rate is for that diagnosis with earlystage BC $(21,26-28)$.

Age may influence RTW after BC because older working women may decide that they do not need to return to their careers. Our results are similar to those of other studies $(27,29)$ in which older patients were less likely to return to work compared to younger patients.

In this study, the RTW rate was higher in women under 45 years of age. It was also higher for women with a college degree, with more than 15 years of work experience, with no pain during scar surgery and with no lymphedema. The literature shows that moral support from work colleagues has an overall positive effect on RTW, albeit not a significant one $(6,10)$. A study by Maunsell and Kennedy showed that some women diagnosed with $\mathrm{BC}$ prefer to devote themselves to their personal lives and thus stop working. These changing priorities previously have been studied previously $(5,26)$. After reassessing their priorities, some women choose to lower their professional responsibilities and devote more time to their families and to themselves (22). In our study, support from the husband, colleagues and managers failed to influence RTW after BC diagnosis. However, in a review, Spelten and colleagues reported that a supportive work environment seemed to facilitate return to work (6). This difference in findings could be attributed to the cultural differences between countries. The rate of heavy lifting at work before diagnosis of $\mathrm{BC}$ was high in patients who returned to work. It appears that changes in responsibility and working hours reflect the nature of their occupation.

A German study conducted a broader analysis of the effects of auxiliary dissection on women's quality of life: five years after diagnosis, 38\% still complained of lymphedema or of limited arm mobility, which was negatively associated with their quality of life (29). Balak and colleagues showed that patients with shoulder function impairment resumed their work about two months later than those without any complaints (9). The factors of RTW identified here should help us to optimize the support provided to patients. This optimization involves informing, reassuring and guiding patients using early and multidisciplinary management.

Managers must be made aware of the importance of the challenges faced by BC patients. Patients can maintain a link with their work environment if each person at work is aware of the issues that women encounter after BC treatment, challenges that extend beyond medical difficulties. This involves a perspective change for all parties involved and a real willingness to reintegrate people who have had cancer. Additional information is needed on initiating an early work resumption support process that will take into account both the person and her environment. The study was conducted during 2000 - 2010. Therefore, this study can demonstrate the long-term effects of 
BC treatment. The findings demonstrate and highlight the importance of "RTW" after BC. Policy makers and legislators need to pay exclusive attention to the long-term effects of BC by considering these factors in employment legislations of Iran. Our findings may help physicians, nurses, supervisors, health educators, health promoters and policy makers determine the predictors that should be considered to improve women's working lives. Several limitations are noted in this study. First, the study sample may not be representative of BC survivors from all parts of the country, since the subjects were employed women, recruited from a specialized oncology center. Second, our study sample was restricted to employed women; thus, they were younger and healthier, compared to the rest of female population.

Finally, the decision to continue to work during illness or to return to work at the end of treatment is important in the quality of life of women with BC. Aside from the economic prejudice, being kept away from one's job can be damaging to one's self-esteem and impair both quality of life and health status. Such conditions, unfortunately, can lead to social isolation.

\section{Acknowledgements}

We would like to thank Mashhad university of medical sciences for their financial support.

\section{Authors' Contributions}

Study concept and design: Fatemeh Azarkish, Khadijeh Mirzaii Najmabadi, Robab Latifnejad Roudsari. Data Gathering: Fatemeh Azarkish, Fatemeh Homaei Shandiz. Interpretation: Fatemeh Azarkish, Khadijeh Mirzaii Najmabadi, Drafting of the manuscript: Fatemeh Azarkish, Khadijeh Mirzaii Najmabadi, Robab Latifnejad Roudsari.

\section{Funding/Support}

This study is approved and funded by the ethics committee of Mashhad university of medical sciences, Mashhad, Iran (code number: 91 - 7 - 3. 910215).

\section{References}

1. de Boer AG, Verbeek JH, Spelten ER, Uitterhoeve AL, Ansink AC, de Reijke TM, et al. Work ability and return-to-work in cancer patients. BrJ Cancer. 2008;98(8):1342-7.

2. Feuerstein M. Defining cancer survivorship. J Cancer Surviv. 2007;1(1):5-7.

3. Peugniez C, Fantoni S, Leroyer A, Skrzypczak J, Duprey M, Bonneterre J. Return to work after treatment for breast cancer: single center experience in a cohort of 273 patients. Bull Cancer. 2011;98(7):E69-79.

4. Tiedtke C, de Rijk A, Dierckx de Casterle B, Christiaens MR, Donceel P. Experiences and concerns about 'returning to work' for women breast cancer survivors: a literature review. Psychooncology. 2010;19(7):677-83.

5. Kennedy F, Haslam C, Munir F, Pryce J. Returning to work following cancer: a qualitative exploratory study into the experience of returning to work following cancer. Eur J Cancer Care (Engl). 2007;16(1):17-25.

6. Spelten ER, Sprangers MA, Verbeek JH. Factors reported to influ- ence the return to work of cancer survivors: a literature review. Psychooncology. 2002;11(2):124-31.

7. Mehnert A. Employment and work-related issues in cancer survivors. Crit Rev Oncol Hematol. 2011;77(2):109-30.

8. Noeres D, Park-Simon TW, Grabow J, Sperlich S, Koch-Giesselmann H, Jaunzeme J, et al. Return to work after treatment for primary breast cancer over a 6-year period: results from a prospective study comparing patients with the general population. Support Care Cancer. 2013;21(7):1901-9.

9. Balak F, Roelen CA, Koopmans PC, Ten Berge EE, Groothoff JW. Return to work after early-stage breast cancer: a cohort study into the effects of treatment and cancer-related symptoms. J Occup Rehabil. 2008;18(3):267-72.

10. Steiner JF, Cavender TA, Nowels CT, Beaty BL, Bradley CJ, Fairclough DL, et al. The impact of physical and psychosocial factors on work characteristics after cancer. Psychooncology. 2008;17(2):138-47.

11. Amir Z, Moran T, Walsh L, Iddenden R, Luker K. Return to paid work after cancer: a British experience. J Cancer Surviv. 2007;1(2):129-36.

12. Roelen CA, Koopmans PC, de Graaf JH, Balak F, Groothoff JW. Sickness absence and return to work rates in women with breast cancer. Int Arch Occup Environ Health. 2009;82(4):543-6.

13. Krause N, Dasinger LK, Neuhauser F. J Occup Rehabil. 1998;8(2):113-39.

14. Johnsson A, Fornander T, Rutqvist LE, Vaez M, Alexanderson K, Olsson M. Predictors of return to work ten months after primary breast cancer surgery. Acta Oncol. 2009;48(1):93-8.

15. Barry MJ, Dancey JE. Instruments to measure the specific health impact of surgery, radiation, and chemotherapy on cancer patients. Cambridge: Cambridge University Press; 2005.

16. Goya M. Iranian Annual Cancer Registration Report 2005/2006. Ministry of Health and Medical Education, Health Deputy [in Persian]. Center Dis Control Prevent. 2007.

17. Ali Mohagheghi M, Mosavi-Jarrahi A. Review of cancer registration and cancer data in Iran, a historical prospect. Asian Pac J Cancer Prev. 2010;11(4):1155-7.

18. Mousavi SM, Montazeri A, Mohagheghi MA, Jarrahi AM, Harirchi I, Najafi M, et al. Breast cancer in Iran: an epidemiological review. Breast J. 2007;13(4):383-91.

19. Khosravi A, Taylor R, Naghavi M, Lopez AD. Differential mortality in Iran. Popul Health Metr. 2007;5:7.

20. Myhren H, Ekeberg O, Stokland O. Health-related quality of life and return to work after critical illness in general intensive care unit patients: a 1-year follow-up study. Crit Care Med. 2010;38(7):1554-61.

21. Johnsson A, Fornander T, Olsson M, Nystedt M, Johansson H, Rutqvist LE. Factors associated with return to work after breast cancer treatment. Acta Oncol. 2007;46(1):90-6.

22. Harirchi I, Karbakhsh M, Kashefi A, Momtahen AJ. Breast cancer in Iran: results of a multi-center study. Asian Pac J Cancer Prev. 2004;5(1):24-7.

23. Mohagheghi MA, Mosavi-Jarrahi A, Malekzadeh R, Parkin M. Cancer incidence in Tehran metropolis: the first report from the Tehran Population-based Cancer Registry, 1998-2001. Arch Iran Med. 2009;12(1):15-23.

24. Feuerstein M, Todd BL, Moskowitz MC, Bruns GL, Stoler MR, Nassif $\mathrm{T}$, et al. Work in cancer survivors: a model for practice and research. J Cancer Surviv. 2010;4(4):415-37.

25. Parizot I, Chauvin P, Paugam S. The moral career of poor patients in free clinics. Soc Sci Med. 2005;61(6):1369-80.

26. Maunsell E, Drolet M, Brisson J, Brisson C, Masse B, Deschenes L. Work situation after breast cancer: results from a populationbased study. J Natl Cancer Inst. 2004;96(24):1813-22.

27. Satariano WA, DeLorenze GN. The likelihood of returning to work after breast cancer. Public Health Rep. 1996;111(3):236-41.

28. Bouknight RR, Bradley CJ, Luo Z. Correlates of return to work for breast cancer survivors. J Clin Oncol. 2006;24(3):345-53.

29. Engel J, Kerr J, Schlesinger-Raab A, Sauer H, Holzel D. Axilla surgery severely affects quality of life: results of a 5-year prospective study in breast cancer patients. Breast Cancer Res Treat. 2003;79(1):47-57. 